\title{
COMISSÃO DE NOVOS MINERAIS E NOMES DE MINERAIS DA IMA: PROCEDIMENTOS E DIRETRIZES SOBRE NOMENCLATURA MINERALÓGICA, 1998
}

\author{
ERNEST H. NICKEL* \& JOEL D. GRICE** \\ Traduzido do original em inglês, THE MA COMMISSION ON NEW MINERAIS AND MINERAL NAMES: PROCEDURES AND \\ GUIDELINES ON MINERAL NOMENCLATURE, 1998, com autorizafao da IMA, por
}

\author{
DANIEL ATENCIO***
}

\begin{abstract}
INTRODUÇÃO A Comissão de Novos Minerais e Nomes de Minerais (CNMNM) da Associação Mineralogica Internacional (IMA) foi estabelecida em 1959, com o proposito de controlar a introdução de novos minerais e nomes de minerais, e de racionalizar a nomenclatura mineralogica. Desde aquela data, o trabalho da CNMNM ganhou apoio preponderante da comunidade mineralogica internacional. A CNMNM e constituida por representantes designados por associações mineralogicas nacionais, e um comite executive que consiste em presidente, vice-presidente e secretario. A lista dos membros atuais e fornecida no Apêndice I.
\end{abstract}

As atividades da CNMNM e suas diversas recomendações para nomenclatura mineralogica foram amplamente divulgadas em um numero significativo de periodicos mineralogicos durante varies anos, e há uma clara necessidade de unir estas informações para prover um relatorio atualizado sobre os procedimentos seguidos pela CNMNM, bem como fornecer diretrizes atualizadas em nomenclatura mineral. Este artigo representaum consenso dos membros da CNMNM, tendo se beneficiado de suas sugestões, Além de incorporar material de comunicações previas sobre nomenclatura mineralogica e procedimentos da CNMNM, inclusive artigos gerais, como os de Hey et al (1961), Fleischer (1970), Donnay \& Fleischer (1970), Mandarine et al. (1984), Dunn \& Mandarine (1988) e Nickel \& Mandarine (1990) e tambem documentos em topicos mais especificos que seráo mencionados no corpo deste artigo. Este documento e, então, uma atualização revisada dos procedimentos empregados pela CNMNM e de diretrizes gerais para nomenclatura mineralogica.

Deve ser ressaltado que a CNMNM não deseja impor um conjunto arbitrario de regras rigidas para a comunidade mineralogica, mas apenas prover um conjunto de diretrizes coerentes que fornecem uma aproximação razoávelmente consistente para a introdução de novos minerais e a aplicação da nomenclatura mineralogica. As diretrizes aqui apresentadas provavelmente aplicam-se razoávelmente bem a grande maioria dos casos, mas inevitavelmente surgirao situaçãos que não se conformam tao prontamente. Como será mencionado varias vezes no texto, cada caso deve ser julgado em seus próprios meritos.

\section{NOVOS MINERAIS Critérios para uma nova espécie mineral Considerações gerais Uma} substancia mineral e um solido que ocorre naturalmente, formado atraves de processes geologicos, na Terra ou em corpos extraterrestrês (Nickel, 1995a). Uma espécie mineral e uma substancia mineral com composição química e propriedades cristalograficas bem definidas, e que merece um nome unico. Critérios gerais para definir espécies minerais são fornecidos abaixo. Na pratica, a maioria das espécies minerais se conforma a este critérios, mas exceções e casos incertos surgirao inevitavelmente, e, em ultima instancia, cada proposta para introduzir uma espécie mineral nova ou mudar a nomenclatura mineralogica deve ser considerada em seus próprios meritos.

O conceito de espécie mineral Uma espécie mineral e definida principalmente com base em sua composição química e suas propriedades cristalograficas, e estes devem ser, então, os fatores-cháves determinantes para a criação de uma espécie mineral nova e um nome mineralógico. Se for encontrado um mineral de composição e/ou propriedades cristalograficas substancialmente diferentes daquelas de qualquer espécie mineral existente, há uma possibilidade de que possa ser uma espécie nova. Uma diretriz geral para critérios composicionais e que pelo menos uma posição estrutural no potencial novo mineral deva ser ocupada predominantemente por um componente quimico diferente daquele que ocorre em posição equivalente em uma espécie mineral existente.

\section{Exemplos:}

1) Hidroxilapatita e fluorapatita cristalizam no sistema hexagonal, com o mesmo grupo espacial, e tern parametros de cela unitaria semelhantes. Elas são consideradas como espécies separadas porque o posição estrutural pertinente e predominantemente ocupada por $\mathrm{OH}$ em hidroxilapatita, e por F em fluorapatita.

2)Esfalerita (ZnS) e "marmatita" ([Zn,Fe]S) são ambos cubicos, com o mesmo grupo espacial e parametros de cela unitaria semelhantes, mas não são considerados como espécies separadas porque a posição estrutural cationica e predominantemente ocupada por $\mathrm{Zn}$ em ambos os casos. "Marmatita" e considerada como uma variedade de esfalerita com $\mathrm{Fe}$ (II).

\section{Substâncias formadas por intervencao humana}

Substâncias antropogenicas, i.e. aquelas feitas pelo Homem, não são consideradas como minerais. Porém, há casos nos quais a intervenção humana na criação de uma substancia e menos direta, e o limite entre mineral e não-mineral pode ser obscuro. Um caso e a ocorrencia de Substâncias novas que devem sua origem, pelo menos em parte, a atividades humanas como mineração ou exploração de pedreiras. Se tais substancias são formadas puramente como resultado da exposição de

* Division of Exploration \& Mining, CSIRO, Private Bag, P.O., Wembley, W.A., 6014, Australia

** Mineral Sciences Division, Canadian Museum of Nature, P.O. Box 3443A, Station 'D', Ottawa, KIP 6P4 Canada

*** Departamento de Mineralogia e Petrologia, Institute de Geociencias - Universidade de São Paulo, Caixa Postal 11348 - $05422-970$ - S3o Paulo - SP - Brasil,

FAX: 55-11-818-4258, e-mail: datencio@usp.br 
rochás ou minerais preexistentes à atmosfera ou aos efeitos de aguas subterrâneas, elas podem ser aceitas, geralmente, como minerais. Entretanto, se sua ocorrência e devida, pelo menos em parte, a interação de minerais preexistentes com substancias de origem não geológica como carga de explosivos, artefatos humanos corroidos ou água contaminada industrialmente, tais produtos não serão, então, considerados como minerais.

Substâncias formadas por combustao geralmente não são consideradas como minerais. Um assunto contencioso e a ocorrencia de substâncias nos produtos de combustao de minas de carvão, pilhás de rejeito ou pantanos com turfa. A origem de um fogo particular e frequentemente difícil de determinar, e então a possibilidade de intervenção humana não pode ser completamente eliminada, nem elimina-se a possibilidade de artefatos humanos que contribuem aos produtos de combustao. Foi decidido, então, que, como uma regra geral, produtos de combustão não serão considerados como minerais no future.

Outro assunto contencioso e se substâncias formadas pela ação do ar ou de água sobre substâncias antropogênicas devem ser consideradas como minerais. Um exemplo famoso e aquele dos "minerais" de Laurium, formados pela reação de agua do mar com escorias metalurgicas antigas. Um problema potencial em aceitar produtos semelhantes como minerais na idade moderna e que uma multidao de substâncias incomuns poderia ser criada de propósito, expondo materials artificials exóticos a influencia de agentes intempericos, e não seria apropriado fornecer para tais substâncias o mesmo status de minerais formados completamente atraves de processes geologicos. Foi decidido, então, que substâncias formadas a partir de materials artificials por agentes geológicos não devem ser aceitas como minerais no futuro (Nickel, 1995a). Porém, a exclusão de tais substâncias do lexico não impede sua descrição como substâncias artificials.

Substâncias que não seriam aceitas como minerais de acordo com os critérios acima, mas que foram aceitas no passado, não serão desacreditadas automaticamente como resultado das novas decisoes, assim como não e intenção da CNMNM voltar o relógio atrás, mas somente estabelecer diretrizes para o futuro.

Substâncias biogenicas Nem sempre e possível estabelecer uma nítida distinção entre substâncias biogênicas, i.e. aquelas produzidas por processes biológicos, e minerais, que normalmente sâo produzidos através de processes geológicos. Por exemplo, esta se tornando cada vez mais claro que muitos dos processos associados com diagenese são influênciados, ate certo ponto, por ação bacteriana, e a biosfera e considerada comumente como uma parte integrante do ciclo geoquímico. Não obstante, e necessário fazer uma distinção formal para prevenir um exército de materials puramente biológicos sendo incorporados ao mundo dos minerais. Algumas substâncias biogenicas, como hidroxilapatita em denies, whewellita em cálculos urinários ou aragonita nas conchas de moluscos, também existem como minerais formados por processes geoquímicos, e então são consideradas como minerais válidos. Porém, substâncias puramente biogenicas que não tern nenhuma contraparte geológica, ou cuja origem não se relaciona em nada a processes geológicos, não são consideradas como minerais.

Substâncias formadas pela ação de processes geológicos sobre material orgânico, como os compostos químicos cristalizados de substâncias orgânicas em folhelho ou de guano de morcego, podem ser aceitas como minerais.

Substâncias amorfas Substâncias amorfas são nãocristalinas e então não satisfazem as exigências normais para espécies minerais. O termo "cristalino", como geralmente usado em mineralogia, significa ordenamento atômico em uma escala que pode produzir uma ordem regular de manchás de difração quando a substância e atravessada por onda de comprimento satisfatório (raios X, elétrons, nêutrons etc.). Entretanto, algumas substâncias geologicamente derivadas como géis, vidros e carvões são não-cristalinos. Tais substâncias podem ser divididas em duas categorias: amorfo - substâncias que nunca foram cristalinas e não difratam; e metamíticas -aquelas que foram alguma vez cristalinas, mas cuja cristalinidade foi destruida por radiação ionizante. Alguns mineralogistas são relutantes em aceitar substâncias amorfas como espécies minerais por causa da dificuldade de se determinar se a substância e verdadeiramente um composto quimico ou uma mistura, e a impossibilidade de caracteriza-la completamente; o termo "mineralóide" e, as vezes, aplicado a tais substâncias. No passado, entretanto, algumas substancias amorfas (por exemplo georgeita, calciouranoíta) foram aceitas como espécies minerais pela CNMNM.

Com técnicas modernas, e possfvel estudar fases amorfas mais efetivamente do que passado. Metodos espectroscópicos associados a uma análise química completa podem identificar, freqiientemente, de maneira inequivoca, uma fase amorfa. De fato, espectroscopias apropriadas (por exemplo IR, NMR, Raman, EXAFS, Mössbauer) podem re velar o ambiente estrutural tridimensional (ligacoes químicas) de curta distancia de cada atomo na estrutura. Claro que, sem a possibilidade de obter uma análise completa de estrutura cristalina, que pode fornecer as coordenadas e a natureza dos átomos, a necessidade de uma análise química completa e mais imprescindivel para materials amorfos que para fases cristalinas.

A base para aceitar uma fase amorfa de ocorrencia natural como uma espécie mineral pode ser uma serie de análises químicas quantitativas completas da substancia, que são suficientes para revelar a composição química homogenea de um numero significativo de graos do espécime, e dados físicoquímicos (normalmente espectroscópicos) que provem a singularidade da fase.

Substâncias metamiticas, se formadas atraves de processes geologicos, são aceitas como espécies minerais se se puder estabelecer com razoável certeza que a substancia original (antes da metamitização) era um mineral cristalino da mesma composição global. Evidências para isto incluem a restauração da cristalinidade por tratamento termico apropriado e a compatibilidade do padrão de difração do produto obtido com a morfologia externa (se existente) do cristal original, por exemplo fergusonita-(Y).

A questão do tamanho Os critérios principals para definir uma espécie mineral são sua composição e estrutura cristalina, e com o desenvolvimento de técnicas analiticas modernas, e agora possfvel obter análise química completa e estrutura cristalina em volumes nanométricos, i.e., na escala de algumas poucas unidades de Ångstrom. Tais dommios submicroscopicos devem ser aceitos como espécie mineral válida? Há uma grande variedade de opiniões sobre este assunto. Por um lado, é discutido que se uma substancia mineral pode ser caracterizada em termos de composição e cristalografia, então deve ser considerada como uma espécie mineral válida. Por outro lado, discute-se que as outras propriedades informadas tradicionalmente para minerais, como cor, dureza, propriedades ópticas etc., não podem ser determinadas em uma area tao reduzida, e que a descrição será, então, incompleta. Além disso, o tamanho da particula descrita deve ser suficientemente grande, de forma que suficiente material tipo possa ser retido para permitir um posterior exame independente para confirmar a caracterização original. Outro argumento contra a aceitação de espécimes nanométricos como espécie mineral válida e que tais substâncias não podem ser exibidas adequadamente em museus mineralógicos. Não foi 
possível chegar a um acordo sobre um tamanho aceitável minimo para que uma substancia mineral seja considerada como uma espécie, e então cada caso deve ser decidido em seus próprios méritos.

Estabilidade sob condições ambientais Muitos minerais foram formados sob condições de alta temperatura e/ou pressão e são metaestaveis sob condições ambientais; outros podem tender a hidratar ou desidratar quando removidos do seu lugar de origem. Tais minerais podem exigir procedimentos especiais para prevenir sua decomposição antes da investigação estar completa. $\mathrm{O}$ uso de procedimentos especiais na investigação não impede a aceitação de uma substancia metaestavel como uma espécie mineral se puder ser caracterizada adequadamente e se respeitar os outros critérios para a aceitação de um mineral.

Polimorfos Minerais polimorfos são aqueles que tern essencialmente a mesma composição química, mas estruturas cristalinas diferentes. $\mathrm{O}$ forma polimórfica de um mineral e considerada como espécie diferente se suas estruturas são topologicamente diferentes. Porém, se as estruturas cristalinas dos polimorfos tern essencialmente a mesma topologia e so diferem em termos de uma distorção estrutural ou na relação de ordem-desordem de alguns dos átomos que compreendem a estrutura, tais polimorfos não são considerados como espécies separadas, e os nomes de tais polimorfos topologicamente semelhantes podem ser distinguidos pela adição de sufixos cristalograficas ao nome mineral, como discutido mais adiante.

Embora a definicao formal de polimorfismo seja restrita a substâncias com composições químicas idênticas, esta limitação rígida e um pouco ampliada para incluir variações químicas relativamente secundárias quando o topologia da estrutura e retida.

\section{Exemplos:}

1) Grafita e diamante são polimorfos de carbono cristalino; ambos tern a mesma composição, mas suas estruturas são topologicamente diferentes, e então minerais como estes são considerados como espécies separadas.

2) Analcima tern varies polimorfos topologicamente semelhántes - cubico, tetragonal, ortorrômbico, monoclinico, triclmico e possivelmente ate trigonal - causados por variações de simetria relativamente pequenas devido a ordenação diferente de $\mathrm{Si}$ e $\mathrm{Al}$, com ocupações diferentes relacionadas da posição estrutural de $\mathrm{Na}$ mais proxima. Tais polimorfos não seráo considerados como espécies separadas.

3)Ortoclasio e microclinio tern essencialmente a mesma composição e estruturas topologicamente semelhantes. De acordo com a pratica atual, estes minerais não seriam considerados como espécies separadas, mas seus nomes são retidos no lexico mineral por razões historicas.

Politipos e politipoides Politipos são substâncias que ocorrem em varias modificações estruturais diferentes, cada uma delas podendo ser considerada como sendo construida pelo empilhamento de camadas de estrutura e composição (quase) idênticas, e com modificações que só diferem na sucessão de empilhamento (Guinier et al,, 1984). Politipóides são substâncias que não se ajustam a definição rigida de um politipo, e incluem minerais com a mesma topologia e com composições um pouco diferentes. Politipos e politipóides não são considerados como espécies separadas e, como os polimorfos topologicamente semelhantes, eles podem ser dist- inguidos pela adição de um sufixo cristalografico ao nome mineral, como indicado mais adiante.

Exemplos:

1)Högbomita existe em vários politipos diferentes hexagonais e romboedricos, devido a variações no empilhámento das camadas estruturais basicas. Estes politipos não são considerados como espécies minerais separadas, e podem ser distinguidos através de sufixos apropriados (ver mais adiante).

2)Pirrotita, Fei- $\mathrm{S}$, onde $\mathrm{x}$ varia entre 0 e 0,12 , existe em varias formas cristalograficas diferentes, devido a variações no ordenamento das vacancias de Fe no reticulo; por causa da composição química variável, os tipos de pirrotita diferentes podem ser considerados como politipoides e não devem ser considerados como espécies separadas.

Interestratificagdes regulates Interestratificações regulares de dois ou mais minerais são aceitas como espécies separadas se os tipos de camadas, suas proporções relativas, composições químicas, e regularidade de interestratificação em três dimensões em escala micrometrica ou nanometrica forem bem documentados. Tal informação pode ser obtida comumente afraves de microscopia eletronica de transmissão (TEM) usando técnicas de imagem de reticulo. Porém, se a evidencia para regularidade de estratificação estiver baseada em dados de difração de raios X, então o critérios de Bailey (1981) deverao ser aplicados.

Exemplo: Uma interestratificação regular de talco e esmectita trioctaédrica esta qualificada como uma espécie mineral separada, aliettita.

Serie homologas e polissomaticas Estruturas homologas são aquelas que consistem em unidades estruturais construidas em principles estruturais comuns e que contem os mesmos elementos químicos, embora em proporções diferentes, e que diferem com respeito ao tamanho das unidades. Uma serie homologa e uma serie de estruturas que podem ser derivadas de um tipo de unidade estrutural basica que usa um tipo de principle de recombinação. Series homologas podem ser classificadas em duas categorias - acrecional e de ajuste variável; combinações dos dois tipos tambem são conhecidas. Uma serie acrecional homologa, tambem conhecida como uma serie polissomatica, e aquela na qual os tipos de blocos de construção (hástes, camadas etc.) e os principles que definem suas relações mutuas permanecem preservados, mas na qual os tamanhos destes blocos variam crescentemente (Veblen, 1991). Um membro de uma serie acrecional homologa pode ser considerado como uma espécie distinta se tiver as propriedades seguintes: a) tamanho caracteristico do bloco de edificio fundamental; b) cela unitaria caracteristica; e c) composição caracteristica ou uma variação composicional limitada (Makovicky, 1989).

\section{Exemplos:}

1) CBODYNUMERADO = As estruturas dos sulfossais lillianita, eskimoita, vikingita, ourayita, gustavita e heyrovskyita podem todas ser interpretadas como consistindo em alternancia de modules tipo galena geminados em (131) no motivo da galena (Makovicky \& Karup-M011er, 1977). Os tamanhos dos modules, os parametros de cela unitaria, e as composições químicas destes minerais são todos diferentes, o que justifica sua existência como espécies separadas.

2) Estruturas compostas de membros do grupo de cilindrita são formadas de dois tipos de camadas, pseudo-hexagonal $(\mathrm{H})$ e pseudo-tetragonal (Q). Cilindrita e franckeíta têm a 
mesma sucessão de estratificação Q-H-Q-H, mas na franckeita a largura da camada de $Q$ e duas vezes a da camada de $\mathrm{Q}$ da cilindrita. Os dois minerais são considerados, então, como espécies separadas. Uma serie homologa de ajuste variável tambem pode ser considerada como homeotipos associados, formando uma estrutura composta. Tal serie e aquela na qual a estrutura consiste em dois tipos blocos de construção mutuamente não-proporcionais alternados. Cada tipo de bloco de construção tern sua própria periodicidade de alcance limitado, e tern periodos de $m$ de um bloco e periodos de $n$ do outro bloco antes que eles se encontrem na mesma configuração como foi observada na origem pre-selecionada. A não-comensurabilidade dos blocos de construção pode ser mono- ou bi-dimensional, e normalmente e conectada com modulação composicional e/ou geometrica de longo alcance de ambos os tipos de camada (Makovicky \& Hyde, 1981). O periodo de longo alcance pode variar dentro de certos limites relativamente amplos por causa de mudanças com incremento no valor de $m$ ou $n$. Devido a isto, as estruturas são infinitamente adaptáveis, e um grande número de possíveis variantes pode resultar. Então, membros individuais de series homologas de ajuste variável não devem ser considerados como espécies separadas (ver mais adiante a seção para sugestões de nomenclaturapara este grupo de minerais).

Exemplo: A estrutura de cilindrita foi interpretada como consistindo em camadas revezadas incomensuraveis de simetria pseudo-tetragonal e pseudo-hexagonal. Varies reticulos coincidentes diferentes foram obtidos para este mineral (Makovicky \& Hyde, 1981), mas estes não qualificam para o estabelecimento de espécies separadas.

Estruturas moduladas Desajustes entre unidades estruturais tambem podem ser acomodados atraves de perturbações estruturais. Se estas perturbaçãos são de natureza periodica, as estruturas resultantes são denominadas estruturas modulares, e geralmente são manifestadas em padrões de difração pelo aparecimento de reflexoes de superestrutura. Variantes moduladas de uma espécie mineral existente não garantem o estabelecimento de espécies separadas.

Exemplo: Na estrutura da antigorita, um desajuste entre as camadas octaedricas e tetraedricas e resolvido por ajustes estruturais que resultam na formação de modulações estruturais com periodicidades diferentes. As varias modulações não são consideradas como espécies separadas.

Serie de SOlução solida Em uma serie contfnua de solução solida binaria, so os dois membros finais são considerados como espécies, e a variação composicional da espécie e considerada para aplicação a partir do membro final ate 50 mol $\%$ da serie; esta e geralmente conhecida como a "regra dos $50 \% "$. Se uma solução solida binaria for incompleta, e a composição de um dos membros finais excede $50 \mathrm{~mol} \%$ por uma quantia pequena, então aquela parte da serie que excede a marca dos $50 \%$ poderia ser considerada, estritamente falando, como uma espécie separada. Porém, para propositos praticos, pode não ser desejavel criar uma espécie nova que defina apenas uma variação composicional muito pequena, e então tais casos devem ser considerados nos seus meritos individuais.

Em series de solução solida multiplas, a regra dos 50\% e interpretada para significar ocupação predominante de uma posição estrutural particular. Assim, se há dois tipos de átomos em uma posição estrutural, a espécie será definida pelo atomo que ocupar pelo menos $50 \%$ daquela posição. Se há mais de dois átomos se substituindo na posição, a espécie e definida pelo atomo predominante na posição. Com a finalidade de definição de espécie, vacancias de posição, comumente rep- resentadas como em formulas químicas, seráo consideradas como átomos.

Em minerais com estruturas complexas e uma multiplicidade de locais estruturais que podem acomodar uma variedade de elementos diferentes, a regra de $50 \%$ pode ser dificil de aplicar, e os autores de propostas de novos minerais que aplicam esta regra para uma posição estrutural particular devem substanciar sua designação por uma análise de estrutura cristalina.

O problema de aplicar a regra dos $50 \%$ para os membros de um grupo complexo e exemplificado pelos minerais do grupo dos anfibolios. $\mathrm{O}$ exemplo dado abaixo mostra que a regra dos 50\% não deve ser aplicada muito rigorosamente, e que um certo grau de liberdade deve ser permitido quando se lida com minerais complexes.

Exemplo: Com uma composição de anfibolio generalizada, expressa pela formula $\mathrm{AB}_{2} \mathrm{CTC}_{22}(\mathrm{OH})_{2}$, a "posição" de $\mathrm{C}$ inclui, na verdade, 5 locais diferentes, e a "posição" de $\mathrm{T}$ na verdade inclui 8 locais. Com os locais de $\mathrm{C}$ capazes de acomodar $\mathrm{Mg}, \mathrm{Fe}^{2+}, \mathrm{Mn}^{2+}, \mathrm{Li}$, e varies elementos menos comuns, há uma grande oportunidade para a proliferação de espécies minerais se a regra dos $50 \%$ para cada posição estrutural for estritamente aplicada. Somado a isto, esta a dificuldade de determinar com precisão populaçãos de posição para elementos com poderes de absorção semelhántes. O Subcomite de Anfibolios decidiu, então, considerar as diferentes posições $\mathrm{C}$ como uma posição composta, e aplicar a ela a regra dos $50 \%$. As posiçãos T, normalmente ocupadas por Si e Al, apresentaram um problema diferente, devido aos petrologos terem considerado, desde longa data, a substituição parcial de Si por Al como sendo de significado petrologico. Os 8 locais de T não foram considerados, então, como uma posição composta, e incrementos menores na relação de Si:Al foram estabelecidos como limites efetivos de espécies.

As vezes, a serie de solução solida não se estende para nenhum membro final, mas, ao inves, as composiçãos agrupam-se ao redor da marca de $50 \%$. Por razões praticas, pode não ser apropriado denotar as composiçãos nos dois lados da marca de $50 \%$ como espécies separadas. Tais casos devem ser considerados nos seus próprios meritos.

Exemplo: Na pentlandita, (Fe,Ni) ${ }_{9} \mathrm{~S}_{8}$, Fe e Ni substituemse um ao outro em uma extensão limitada, com composições centradas ao redor de $\mathrm{Fe}_{4}, 5 \mathrm{Ni}_{4}, 5_{8}$. Não se julgou necessario dividir pentlandita em duas espécies, uma com Fe dominante e outra com Ni dominante.

Alguns detalhes adicionais que se aplicam a séries de solução solida multiplas e parciais são fornecidos em Nickel (1991).

\section{Exigencies para a aprovação de novos minerais}

Antes de um mineral novo e seu nome poderem ser aceitos na literatura, eles devem ser aprovados pela CNMNM. Para obter esta aprovação, o investigador senior deve submeter uma proposta ao presidente da CNMNM (ver Apêndice I), ou diretamente, ou atraves de um comite nacional de novos minerais, se apropriado; no momento, comites nacionais executam esta função na Russia e na China.

E importante que uma proposta de mineral novo seja submetida para aprovação antes da publicação. Tal submissão deve conter tanta informação quanto possivel de forma que a CNMNM possa julgar a válidade da proposta adequadamente. Idealmente, uma proposta de mineral novo deve conter a informação seguinte:

- Nome proposto e argumento para sua seleção.

- Descrição da ocorrencia (ocorrencia geografica e geologica, paragenese, e uma lista de minerais associados, particularmente aqueles em aparente equilfbrio com o mineral novo).

- Composição química e método de análise. 
- Formula química - empirica e simplificada.

- Cristalografia - sistema cristalino, classe cristalina, grupo espacial, grupo pontual, parametros de cela unitaria, volume de cela unitaria, niimero de unidades de formula por cela unitaria, e dados de po de difração de raios X.

- Estrutura cristalina - descrição geral, populações de posição, formula estrutural, fator de confiabilidade.

- Aparencia geral e propriedades fisicas - tamanho do grao ou cristal, morfologia, tipo de agregado, cor, trago, brilho, transparencia, dureza, tenacidade, clivagem, particao, fratura, densidade - medida e calculada (Mandarino, 1981a).

Propriedades ópticas

a) minerais não-opacos: carater optico (isotropico ou anisotropico; uniaxial ou biaxial), sinal optico, indices de refração, $2 \mathrm{~V}$, dispersão, orientação, pleocroismo e absorção. $\mathrm{O}$ mdice de compatibilidade que usa a relacao de GladstoneDale (Gladstone \& Dale, 1864) tambem deve ser calculado (Mandarino, 1981b; Bloss et al., 1983).

b) minerais opacos: cor em luz refletida plano-polarizada, reflexoes internas, reflectancia, birreflectancia, pleocroismo e anisotropia. A reflectancia deve ser medida com relação a um padrão de reflectancia aprovado pela Comissão de Microscopia de Minerios da IMA (COM-IMA), idealmente de 400 a $700 \mathrm{~nm}$ em intervalos de $20 \mathrm{~nm}$. A exigencia mínima e para dados de reflectancia nos comprimentos de onda 470,546,589 e $650 \mathrm{~nm}$. Quando são provides dados para medidas em oleo, o oleo usado deve concordar com o padrão Alémao DIN 58,884; esta e outras recomendações da COM-IMA estão contidas em Griddle \& Stanley (1993).

Outros dados: comportamento termico, espectro infra-vermelho, resposta a testes químicos etc.

- Material tipo: O material tipo deve ser designado de acordo com os critérios publicados por Dunn \& Mandarino (1987) e depositado como material de referenda permanente em pelo menos um museu principal ou uma coleção mineral nacionalmente reconhecida (Dunn, 1988).

- Relação com outras espécies.

- Referencias relevantes

- Quaisquer outros dados que clarifiquem partes difíceis da descrição.

Reconhece-se que nem sempre pode ser possivel obter todos os dados acima; em tais casos, o autor deve fornecer razões para as omissoes. De importancia particular e o calculo do conteudo de $\mathrm{K}_{2} \mathrm{O}$, quando esta não for analiticamente determinada. $\mathrm{Se} \mathrm{H}_{2} \mathrm{O}$ for calculada por diferenga, o metodo de calculo deve ser claramente especificado e, se possivel, a evidencia para a presenga de $\mathrm{H}_{2} \mathrm{O}$ deve ser provida. Tambem, ampla justificação deve ser dada para a distribuição de hidrogenio em $\mathrm{H}_{2} \mathrm{O}, \mathrm{OH}$ ou $\mathrm{H}_{3} \mathrm{O}$.

Por causa de grandes diferengas na quantidade e tipo de informação que pode ser obtida do estudo de um espécime mineral particular, não e pratico especificar o minimo irredutivel de informação requerido para um mineral a ser aprovado; cada proposta deve ser considerada em seus próprios meritos.

Um esbogo geral dos procedimentos envolvidos no estabelecimento de uma espécie mineral nova e fornecido por Dunn (1977). Para auxiliar os potenciais autores de propostas de novos minerais, uma lista de conferencia foi elaborada (Mandarino, 1987) e deve ser completada como parte da proposta. Podem ser obtidas copias desta lista de conferencia oficial do presidente da CNMNM ou de um dos representantes nacionais (Apêndice I). Diretrizes em alguns aspectos de propostas de novos minerais são determinadas abaixo.

Para auxiliar cientistas que não tern todas as facilidades técnicas para obter alguns dados importantes para a definição completa de um mineral novo, a CNMNM (por seu presidente ou secretario) pode solicitar de alguns de seus membros, ou especialistas de algum subcomite, a colaboração com estes cientistas para melhorar suas propostas.

As vezes acontece que especialistas não-mineralógicos como cristalografos ou químicos publiquem uma descrição de estrutura cristalina de um mineral novo que não foi aprovado oficialmente pela CNMNM. Tais descrições não devem incluir um nome para o mineral.

Se o espécime mineral inteiro foi consumido durante o curso da investigação, e por conseguinte nada do espécime resta a ser depositado em uma coleção apropriada, a aprovação para o novo mineral não será dada; isto acontece porque algum material sempre deve permanecer para possível novo exame posterior.

\section{Tratamento de uma proposta de mineral novo}

Quando o presidente da CNMNM recebe uma proposta de mineral novo de autores, ou diretamente ou pelo comite de minerais novos nacional no pais de origem, ele acusara o recebimento da proposta, e podera escrever aos autores solicitando mais informações se considerar desejavel, ou podera mostrar possiveis objeções ao mineral ou ao nome. Se os autores assim desejarem, o presidente devera submeter uma proposta a CNMNM, mesmo que ele não concorde com ela. Em tais casos, o presidente informara os autores que ele fornecera suas razões sobre a inadequação da proposta no item "Observações do presidente". O resume da proposta, elaborado pelo presidente, e enviado por correio via aerea a cada membro da CNMNM, e são permitidos aproximadamente 60 dias para recebimento dos votos.

Os membros da CNMNM são urgidos não so a votar, mas tambem a comentar em detalhes. $\mathrm{O}$ presidente tern autorização para suspender a votação de uma proposta para hábilitar mais informação a ser obtida, ou ele pode pedir uma segunda votação em uma proposta se, na opinião dele, comentarios importantes tiverem sido feitos por membros da CNMNM e que devam ser vistos por todos os membros. Segundos votos tern os mesmos periodos de votação (aproximadamente 60 dias) e requerem as mesmas maiorias que aquelas para propostas originais (ver abaixo). Qualquer membro da CNMNM que tenhá objeções a uma proposta pode pedir para o presidente suspender a votação ou pedir uma nova votação, mas a decisão final para fazê-lo será do presidente.

Resumes de propostas que lidam com minerais opacos podem ser enviados a alguns membros do IMA-COM a discrição do presidente. Similarmente, o presidente pode submeter resumo de qualquer proposta a outros especialistas para opiniões aconselhádoras. Tais conselheiros não votam, mas seus comentarios são considerados pelo presidente. Objeções serias levantadas por qualquer conselheiro seráo tratadas pelo presidente como especificado acima.

Propostas que lidam com minerais que pertencem a grupos de minerais para os quais foram organizados subcomites pela CNMNM podem ser enviadas ao presidente do subcomite apropriado para circulação entre os membros do subcomite se o presidente da CNMNM julgar tal ação aconselhável. Os membros do subcomite são convidados a submeter opiniões, e objeções serias levantadas por eles seráo tratadas como especificado acima.

Se duas ou mais propostas para o mesmo mineral novo são recebidas pela presidente, a proposta que chegou primeiro no escritorio do presidente tera prioridade. Podem ser feitas exceções se a proposta do mineral novo foi submetida por um comite nacional de novos minerais e se o presidente da CNMNM receber notificação anterior do recibo da proposta pelo comite nacional.

Um mineral novo proposto será considerado aprovado se mais que metade $(1 / 2)$ dos membros da CNMNM votar na proposta, e se mais que dois tergos (2/3) destes membros votar 'sim'. Um nome proposto será considerado aprovado se mais 
que metade $(1 / 2)$ dos membros que votarem na proposta votarem 'sim'. Avaliando os resultados da votação, uma abstenção e considerada como um voto negativo, o que sugere que informação adicional e requerida. Depois que a votação em uma proposta e completada, o presidente envia os resultados aos membros da CNMNM e ao autor da proposta. Ele inclui os comentarios dos membros votantes, mas não são revelados os votos individuals dos membros. Reconsideração de votos contraries pode ser pedida a qualquer momento por um autor se dados novos significativos ou interpretações novas são obtidos. Se um mineral e aprovado, mas não o nome, um nome novo deve ser solicitado pelo presidente quando ele notificar o autor dos resultados da votação. Em casos de votação repetida, as aprovações do mineral e do nome requerem as mesmas maiorias que na votação original.

Autores que descreveram novos minerais sem nomes não tern nenhum direito de prioridade na denominação subseqiiente de tais minerais. Porém, como um gesto de cortesia, e recomendado que uma pessoa que propoe um nome para um mineral previamente não denominado comunique-se com os autores originals do mineral não denominado. Qualquer nome novo proposto subseqiientemente tern que ser aprovado pela CNMNM, como tambem o mineral para o qual o nome e proposto.

A publicação de um nome não aprovado, ou a publicação de um nome para um mineral não aprovado não e aceitavel, e os editores de periodicos devem evitar a introdução de tais nomes.

GRUPOS DE MINERAIS A nomenclatura de grupos de minerais geralmente e tratada por subcomites que incluem os especialistas no grupo sob consideração, e pelo menos um membro da CNMNM. Os seguintes subcomites foram estabelecidos no passado: Pirocloro, Anfibolios, Piroxenios, Sulfossais, Micas, Zeolitas, Minerais do Grupo da Platina, Nomenclatura, e Minerais Sem Nome.

A criação de um subcomite e sua composição devem ser aprovadas pela CNMNM. E esperado que o subcomite formule recomendações para a nomenclatura de minerais do grupo sob consideração, e estas recomendações são submetidas a CNMNM para aprovação por um procedimento de votação. As recomendações do subcomite são consideradas como sugestões, com a decisão final relativa a adoção das recomendações ficando a cargo da CNMNM.

Propostas para a criação de novos subcomites devem ser submetidas ao presidente da CNMNM. Se o estabelecimento de um novo subcomite e aprovado, o secretario da CNMNM (ver Apêndice I) e autorizado a lidar com assuntos que envolvem o subcomite.

\section{MUDANQAS NA NOMENCLATURA EXISTENTE}

Geral Mudanças na nomenclatura mineralógica existente, inclusive a redefinição ou desacreditação de espécies minerais existentes, a redenominação de minerais, ou a reválidação de nomes de minerais desacreditados ou obsoletos, devem ser aprovados pela CNMNM antes da publicação. Para este fim, uma proposta satisfatoria deve ser submetida ao vice-presidente da CNMNM (ver Apêndice I).

Uma lista de mudanças na nomenclatura aprovadas pela CNMNM desde 1987 e apresentada no Apêndice II.

Redefinição Avangos no conhecimento como aqueles resultantes de refinamentos de estrutura ou novos conhecimentos químicos que ampliem limites conhecidos de solução solida não precisam, em geral, ser submetidos a CNMNM. Porém, e requerida aprovação da CNMNM se e proposta a redefinição de um mineral: a) em bases estruturais; b) adicionando ou subtraindo um ou mais componentes quimicos considerados essenciais para a definição; ou c) propondo limites composicionais em uma serie de solução solida que não são compativeis com a definição existente da regra dos $50 \%$ (ou seu equivalente em sistemas de multicomponentes). No caso de duvida, os autores são convidados a consultar o vice-presidente da CNMNM.

Se um mineral e demonstrado ser uma mistura e um dos componentes e, por outro lado, novo, o nome normalmente deve ser transferido a fase nova.

A redefinição de uma espécie mineral requer a revisão da literatura sobre o mineral a ser redefmido, um novo exame do espécime tipo (ver abaixo), a comparação dos dados novos com os originals, e a justificativa para redefinição.

Desacreditação Um mineral ou nome de mineral podem ser desacreditados se puder ser demonstrado que o mineral e identico a um outro que tern prioridade, ou se o nome e improprio. As exigências para desacreditar uma espécie mineral ou nome são semelhantes àquelas para redefinição (ver acima), e foram esbogadas por Dunn (1990).

Revalldafao Um mineral que foi desacreditado ou caiu em desuso pode ser reválidado se um novo exame mostrar que o mineral conforma-se aos critérios normais para uma espécie mineral distinta ou que e uma mistura que contem uma espécie mineral nova. As exigências para reválidação de uma espécie mineral são semelhantes aquelas para redefinição, mencionadas acima.

Espécimes tipo Sempre que possivel, a redefinição, desacreditação ou reválidação de um mineral devem estar baseadas em um estudo do material tipo. Se um espécime tipo existe e se a descrição original, apesar de imperfeita, representa uma aproximação razoável do material no espécime, o mineral será defmido por referenda ao material tipo em lugar da descrição original. Isto significa que erros na descrição original não podem levar a desacreditar um mineral a menos que a descrição original fosse tao grotescamente inexata que, nas palavras de J.D. Dana (1868) "um reconhecimento do mineral por meio dela e impossivel"

Se o material tipo não puder ser obtido para estudo, o investigador pode propor um neotipo a CNMNM, declarando claramente os esforgos para buscar o espécime tipo original, e provendo evidencia satisfatória para a identidade do neotipo com o original. Tanto a aceitação do neotipo quanto a aprovação da proposta são de responsabilidade da CNMNM.

\section{Preparação de uma proposta de nomenclatura}

Uma proposta para mudar a nomenclatura mineralogica deve incluir toda informação pertinente, inclusive um resumo da descrição original do mineral, uma revisão de trabalhos subseqiientes, a submissão de dados novos, e recomendações para mudança.

Se um ou mais dos autores originais do mineral a ser desacreditado ou redefmido estao vivos, o autor da proposta de desacreditação ou redefinição deve escrever aos autores originais solicitando-lhes um comentario sobre a proposta, e este comentario deve acompanhar a submissão a CNMNM.

Uma proposta para mudança de nomenclatura deve ser enviada ao vice-presidente da CNMNM que esta autorizado a escrever ao autor mostrando possiveis deficiencias na proposta e fazendo sugestões para sua melhoria. A proposta, modificada se necessario, e submetida então aos membros da CNMNM como um rascunho de proposta, convidando-os a comentar. Tais comentarios, se houver, são remetidos aos autores da proposta, solicitando-os a responder aos comentarios, modificar a proposta, ou retira-la, como apropriado. Se a proposta não for retirada, uma proposta emendada e submetida aos membros da CNMNM para um voto formal, junto com os comentarios na proposta rascunho e as re- 
spostas dos autores. O procedimento de votação e semelhante aquele seguido no caso de propostas de novos minerais, e pelo menos uma maioria de dois tergos e exigida para aprovar tais propostas.

\section{DIRETRIZES GERAIS PARA NOMENCLATURA} MINERALOGICA Escolha de um novo nome de mineral A responsabilidade para a escolhá de um nome para um novo mineral e primariamente do autor ou dos autores da descrição original, embora o nome deva ser aprovado em ultima instancia pela CNMNM. Um mineral e denominado comumente para a localidade geografica de sua ocorrencia, para o descobridor do mineral (exceto se ele for o autor), para uma pessoa proeminente no campo de mineralogia, ou para uma propriedade particular do mineral.

A denominação de minerais para organizações ou grupos comerciais que não contribuiram de forma especifica e importante a mineralogia será desencorajada para evitar comercialização impropria da nomenclatura.

Se o mineral for denominado para uma ocorrencia geografica, deve ser tornado cuidado para assegurar que a ortografia conforma com aquela em uso para a localidade, e não deve ser baseada em traduções.

Se o mineral for denominado em homenagem a uma pessoa vivente, a permissão daquela pessoa deve ser obtida pelo autor, e isto deve ser feito antes da submissão da proposta a CNMNM. Quando decidir denominar um mineral para uma pessoa, e bom recordar o preceito de J. D. Dana (1854): "Deve ser lembrado que o uso de nomes de pessoas eminentes em outras ciencias, ou de pessoas alheias a todas as ciencias, esta totalmente em desacordo com o bom uso e decoro; Além disso, uma tentativa de lisonja aos politicos que se sobressaem e degradante a ciencia, e nunca será suficientemente rechágada". Se o mineral e denominado em homenagem a uma pessoa cujo nome contem um espago ou uma letra maiuscula, o nome deve ser modificado para os eliminar, por exemplo mcnearite, não mcNearite;joesmithite, não joe smithite. Caso contrario, a ortografia original do nome da pessoa deve ser retida.

Embora a CNMNM não tenha uma política fixa no uso de nomes pessoais compostos, alguns membros julgam que eles devem ser desencorajados, particularmente quando ficam incomodos ou cacofonicos, ou quando distorcem desnecessariamente os verdadeiros nomes do individuo que esta sendo supostamente homenageado.

Nomes de minerais propostos em idiomas que usam alfabeto diferente do latino devem ser transliterados para o alfabeto latino pelo autor do nome de acordo com o sistema em operação prevalecente no pais de origem. Tais nomes transliterados devem ser informados, em periodicos nacionais, por exemplo, quando o nome do mineral e escrito de acordo com outros alfabetos ou regras fonéticas. Devem ser retidas marcas diacnticas onde quer que possivel, mas e reconhecido que nem todos os estabelecimentos de impressão tern as instalações necessarias para imprimir todos os tipos de marcas diacríticas; em tais casos, estas podem ser omitidas.

A reutilização de um nome desacreditado ou obsolete para um mineral novo ou redefinido será desencorajada, exceto quando o mineral novo e originalmente um componente de uma mistura descrita como um unico mineral; em tal caso, o nome original pode ser transferido a fase nova A reutilização de um nome desacreditado tambem pode ser permitida se houver uma boa razao pela qual o nome desacreditado seja particularmente apropriado para o mineral em questão, e o nome desacreditado ou obsolete não apareceu na literatura ativa (com exceção do artigo de sua desacreditação) durante cinquenta anos. Uma proposta para reutilizar um nome obsolete deve ser acompanhada ou deve ser precedida por uma proposta para desacreditar o nome obsolete. Se a CNMNM não aprovar uma proposta para reutilizar um nome desacreditado, o autor da proposta não tern nenhuma prioridade pelo uso do nome desacreditado, embora ele esteja livre para proper o nome novamente em um momento future.

A reutilização de um nome obsolete ou desacreditado não e permitida se o nome foi usado de maneira expressiva fora do campo da mineralogia (por exemplo em petrografia, metalurgia, paleontologia etc.), ou indicar dois ou mais minerais.

Se uma substancia artificial recebeu um nome, e um mineral que corresponde aquela substancia e descoberto subseqtientemente, o nome dado a substancia artificial não necessariamente tern que ser aplicado ao mineral.

$\mathrm{O}$ nome deve ser suficientemente diferente daqueles existentes para prevenir confusão, tanto no idioma do autor e em outros. A nomenclatura mineralogica existente ja exibe varios exemplos de nomes desafortunados que são facilmente confundidos; nomes como celadonita e caledonita, ou mallardite e malladrite podem ser facilmente redigidos erradamente; nomes como rhodesita, rhodizita e rhodusita são foneticamente bem parecidos. A introdução de novos nomes que possam criar problemas semelhantes deve ser evitada.

Se o mineral novo e claramente e simplesmente relacionado a um ja conhecido, e muito desejavel que esta relação seja indicada no nome novo, por exemplo clinoenstatita para o dimorfo monoclinico da enstatita, ou magnesiocopiapita para o analogo de $\mathrm{Mg}$ da copiapita. Tal nome deve consistir em um so palavra (por exemplo magnesiocopiapita, não magnesia copiapita).

Devem ser feitos esforgos para escolher um nome simples em lugar de um excessivamente complicado, que possa ser diffcil de ler ou pronunciar. $\mathrm{O}$ uso de nomes excessivamente longos deve ser evitado, pois estes podem causar dificuldades em pronunciação, tabulações, e bancos de dados de computador.

Minerais de terras-raras $\mathrm{O}$ nome de um mineral com elementos de terras-raras essenciais (REE), ou os elementos químicamente relacionados $\mathrm{Y}$ ou $\mathrm{Sc}$, devem apresentar um sufixo que indica o elemento de terras-raras dominante, por exemplo bastnasita-(Ce), e se um mineral novo com a mesma estrutura e composição analoga, mas com um elemento de terras-raras dominante diferente, e descoberto, deve ser dado um nome que seja analogo ao do mineral existente, por exemplo bastndsita-(Y). Um sufixo deste tipo e conhecido como modificador de Levinson em homenagem a pessoa que introduziu este procedimento (Levinson, 1966). Uma clarificação subsequente (Bayliss \& Levinson, 1988) especifica que mais de um simbolo quimico so pode ser juntado se os elementos ocupam locais diferentes na estrutura cristalina. Uma compilação de minerais de terras ${ }^{\wedge}$ raras, adequadamente sufixados, foi incluida como um Apêndice em Nickel \& Mandarine (1990).

Um exemplo de uma situação que pode surgir e aquela na qual um mineral apresenta uma posição estrutural particular ocupada por Ca e REE, e a soma de elementos REE (em proporções molares) e maior que a de $\mathrm{Ca}$, mas os elementos REE individualmente apresentam-se em proporções inferiores ao Ca. Em tal caso, o mineral e considerado como um mineral de terras-raras, com um modificador de Levinson que especifica o REE predominante.

Modificadores de Levinson estendidos Como notado acima, modificadores de Levinson são usados primariamente na nomenclatura de minerais de terras-raras. Em alguns casos, porém, o procedimento foi estendido a outros grupos de minerais que podem center diferentes elementos substituindo-se em um ou mais locais estruturais, por exemplo jahnsita e pumpellyita. Em zeolitas, tais modificadores são 
usados para indicar cations trocaveis. Em geral, o uso de modificadores de Levinson estendidos e aceitavel em cases onde um unico elemento substituinte e sufixado, mas sufixos que consistem em multiples elementos são condicionalmente aceitaveis em casos onde a estrutura e complexa, e o uso de tais sufixos simplifica a nomenclatura.

Modificadores Em nomenclatura mineralogica, e importante distinguir o nome formal de modificadores que podem acompanhár o nome, sem estar conectados a eles. Um modificador não e considerado parte do nome do mineral, e normalmente indica uma variante composicional, por exemplo manganotantalita com $\boldsymbol{F e}(\boldsymbol{H})$ onde com Fe(II) e o modificador que indica a presenga de um pouco de Fe(II), e manganotantalita e o nome formal.

Como modificadores não são considerados parte do nome do mineral, eles devem ser ignorados na preparação de indices alfabeticos. Ocasionalmente um modificador e determinado na forma de um prefixo quimico hifenizado, por exemplo Li-tosudita, em lugar de tosudita com Li ou tosudita contendo litio. Tal uso e incorreto e deve ser evitado.

Nomes de variedades Os nomes existentes de variedades de minerais como ametista, kunzita etc., que não são considerados como espécies, não são da jurisdição da CNMNM, e não são, então, regulamentados. A introdução de novos nomes de variedades, porém, será desencorajada, pois tende a criar confusão na literatura mineralógica.

Nomenclatura de grupos de minerais Como notado acima, subcomites foram estabelecidos para varies grupos de minerais complexes. Alguns destes subcomites produziram relatorios que foram aprovados pela CNMNM, e estes relatorios foram publicados em varies periodicos. Os relatorios que incluem diretrizes para a nomenclatura de minerais que fazem parte destes grupos são muito complexes para sere resumidos adequadamente aqui; assim, os lei tores são aconselhádos a consultarem os relatorios publicados destes subcomites, como segue: pirocloro - Hogarth (1977); piroxenios - Morimoto (1990); minerais do grupo da platina -Hárris \& Cabri (1991); anfibolios - Leake et al. (1997); micas - Rieder et al. (no prelo); e zeolitas - Coombs et al. (1997).

Em geral, nomes de grupos de minerais menos complexos estao bem estabelecidos na literatura mineralogica, e freqiientemente um dos nomes de espécie dos minerais que fazem parte do grupo e usado para este proposito. $\mathrm{O}$ uso de tais nomes de grupo não e regulamentado pela CNMNM, mas a criação de um nome novo tem que ter a aprovação da CNMNM.

Nomenclatura de politipos, politipoides e polimorfos $\mathrm{O}$ sistema aprovado para denotar politipos e a notação de Card modificada, recomendada pela Associate Mineralogica Internacional e pela União Internacional de Cristalografia (Bailey etal, 1978;Guinier et al., 1984;Nickel, 1998). Ela consiste no nome do mineral seguido por um sufixo em italico, hifenizado, que inclui um caractere alfabético para indicar sistema cristalino, precedido por um simbolo numerico para indicar multiplicidade da unidade estrutural, proposto originalmente por Ramsdell (1947). Este sistema tambem pode ser usado para polimorfos topologicamente semelhantes e para politipoides. Os caracteres alfabéticos a serem usados nos sufixos são como segue: cubico - $C$; tetrago- nal - $Q$ (de quadratico); hexagonal - $H$; trigonal - $T$; romboedrico - $R$; ortorrombico - $O$; e triclinico - $A$ (de anortico).

Exemplos:

1) Muscovita- $1 M$ e o politipo monoclinico da muscovita $\operatorname{com} c=10 \mathrm{~A}$; muscovita- $1 M_{1}$ e o politipo monoclinico da muscovita com $c-20 \AA \AA$; e muscovita-STe o politipo trigonal da muscovita $\operatorname{com} c-30 \AA$

2) Analcima tem varies polimorfos topologicamente identicos causados por graus diferentes de ordenação de $\mathrm{Al}$ e $\mathrm{Si}$ nos locais estruturais tetraedricos. Os polimorfos diferentes são distintos pelos sufixos $-1 \mathrm{C},-1 Q$, $-\mathrm{IM}$ etc.

Nomenclature de domínios nanométricos Se um dominio de dimensões nanometricas em um grão mineral maior tem uma composição ou estrutura cristalina sem igual mas não e suficientemente grande para qualificar uma espécie mineral, não deve ser dado um nome mineral distintivo. Se for julgado necessário se referir a tal domínio através de nome, deve-se reter o nome do mineral hospedeiro, com a adição de um sufixo apropriado, indicando a natureza cristalografica e/ou composicional do dominio. Tais sufixos não requerem aprovação pela CNMNM.

Nomenclatura de series homologas de ajuste variável Não devem ser dados nomes individuals aos membros de series homologas de ajuste variável (ver seção previa). Ao inves, um modificador descritivo opcional pode ser juntado e pode ser descrita a combinação entre os blocos de construção. Os conteudos do simbolo juntado variarao de acordo com a precisão requerida ou o metodo usado, devem center a palavra 'homologo', e devem ser incluidos por parenteses. Um exemplo e "cilindrita, omologo $(19,13) Q /(30,12) H^{\prime \prime}$ para um homologo da serie da cilindrita com um bloco de construção tetragonal (quadratico) de 19 por 13 unidades que e comensuravel com um bloco hexagonal de 30 por 12 unidades.

Prefixes em nomes de minerais Ao aplicar prefixes composicionais para nomes de minerais, e recomendado que prefixes derivados do latim sejam usados em vez daqueles derivados de outras linguas (Hey e Gottardi, 1980), por exemploferro- em vez de eisen-, natri- em vez de soda-, ou estano- em vez de olovo-.

Prefixes são uma parte integrante do nome do mineral, e geralmente devem ser tratados como tal na preparação de compilações alfabeticas ou indices. Porém, uma exceção pode ser feita no caso de simbolos antepostos como letras gregas ou seus equivalentes latino que podem ser posicionados depois do nome principal em listagens alfabeticas; por exemplo $\beta$-roselita pode ser escrito como roselita- $\beta$ ou roselita-beta.

O prefixo para so deve ser usado para nomes de dimorfos ou polimorfos de minerais conhecidos. O prefixo meta so deve ser usado para nomes de minerais menos hidratados que minerais conhecidos.

Hífens em nomes de minerais Hífens são usados em nomes de minerais para conectar simbolos sufixados, como sufixos de politipos e modificadores de Levinson. $\mathrm{O}$ uso de um hifen para distinguir um prefixo do nome raiz será desencorajado, mas onde um nome sem hifen e desastroso e um hífen auxilia a decifrar o nome, pode ser usado, por exemplo bario-ortojoaquinita.

Nota do tradutor: no original deste trabalho, em inglês, "é recomendado que adjetivos derivados do latim sejam usados sempre que possível (Hey e Gottardi, 1980), por exemplo natrian vs sodian, e kalian vs potassian. Os modificadores recomendados por Schaller (1930) acháram aceitação geral, e eles foram aumentados pelas adições feitas pela lista mais completa de modificadores publicada por Nickel \& Mandarine (1987). Ao construir um modificador que não esta na lista, o oan do final será usado para o fon com a mais baixa valência, e ian para a mais alta. Se a valência de um elemento em um mineral particular não e conhecida, o modificador derivado do mais provável, ou mais comum, estado de valência do elemento deve ser usado". 


\section{Nomes de minerais para substâncias sinteticas}

Nomes de minerais inalterados não devem, em geral, serem usados para substâncias sinteticas que correspondem a minerais existentes, análogos químicos de minerais existentes, ou minerais hipoteticos. Porém, substâncias sinteticas que correspondem a minerais existentes podem receber nomes de minerals se tais nomes são modificados adequadamente para indicar claramente sua origem sintetica (Nickel, 1995b), ou se a origem sintetica de tais substâncias e mencionada claramente.

\section{PUBLICAQAO DAS DESCRIBES DE MINERAIS} APROVADOS $\mathrm{O}$ artigo publicado que descreve o mineral novo deve incluir informação suficiente, comparavel aquela fornecida na proposta para a CNMNM. Publicação de um resume breve, no qual so alguns dos dados são inclufdos deve ser evitada.

Autores de propostas aprovadas devem publicar as descrições dos minerais destas propostas em dois anos apos serem notificados da aprovação pelo presidente ou vice-presidente. Se não forem publicadas as descriçãos de novos minerals, desacreditaçãos, redefiniçãos ou revalidaçãos dentro daquele prazo, as propostas ja não serão consideradas como aprovadas. Qualquer extensão deste prazo final deve ser aprovada pelo presidente ou vice-presidente, conforme o caso.
RECOMENDAQOES AOS EDITORES Os editores de periodicos estarao prestando um grande serviço a comunidade geocientifica se cooperarem plenamente com a CNMNM. Todos os aspectos da nomenclatura em manuscritos submetidos devem ser avaliados de acordo com as diretrizes aqui apresentadas, e deve-se assegurar que os autores submeteram todos os itens relativos a nomenclatura mineralogica a CNMNM, e que suas propostas foram aprovadas. A menos que tenhám prova definitiva de aprovação, os editores devem consultar seus representantes nacionais na CNMNM, ou membros executives da CNMNM. Os editores devem ser particularmente cautelosos quanto a aceitação final de um artigo que contem frases como "foi submetido" ou "será submetido" a CNMNM. A aceitação de tais documentos deve ser adiada ate que se produzam evidências de que a nomenclatura foi aprovada pela CNMNM.

No caso de novos minerais, os editores devem insistir na evidencia de que um espécime tipo do novo mineral foi depositado em pelo menos um museu renomado ou uma coleção mineralogica nacionalmente reconhecida. Esta informação devera ser incluida no artigo publicado.

Seria importante que todos os periodicos que publicam artigos mineralógicos incluissem o texto seguinte em suas instances aos autores:

"Este periodico segue as regras da Comissdo de Novos Minerais e Nomes de Minerais da IMA em todos os assuntos relativos a nomes de minerais e nomenclatura mineralogica".

\section{Referencias}

Alien, F. M. (1992): Mineral definition by HRTEM: Problems and opportunities. Reviews in Mineralogy, 27 (P. R. Buseck, ed.), 289-333.

Bailey, S. W. (1981): A system of nomenclature for regular interstratifications. Canadian Mineralogist, 19,651-655.

Bailey, S. W., Frank-Kamenetskii, V. A., Goldsztaub, S., Kato, A., Pabst, A Schulz, H., Taylor, H. F. W., Fleischer, M. \& Wilson, A. J. C. (1978): Report of the International Mineralogical Association (IMA)-International Union of Crystallography (IUCr) joint meeting on nomenclature. Canadian Mineralogist, 16, 113-117.

Bayliss, P. \& Levinson, A. A. (1988): A system of nomenclature for rare-earth mineral species: revision and extension. American Mineralogist, 73, 422-423.

Bloss, F. D., Gunter, M., Su, S-C, \& Wolfe, H. E. (1983): Gladstone-Dale constants: a new approach. Canadian Mineralogist, 21, 93-99.

Coombs, D.S., Alberti, A., Armbuster, T, Artioli, G., Colella, C., Galli, E., Grice, J.D., Liebau, F., Mandarine, J.A., Minato, H., Nickel, E.H., Passaglia, E., Peacor, D.R., Quartieri, S., Rinaldi, R., Ross, M., Shepard, R.A., Tillmamms \& E., Vezzalini, G. (1997) Recommended nomenclature for zeolite minerais: report of the Subcommittee on Zeolites of the International Mineralogical Association, Commission on New Minerais and Mineral Names. Canadian Mineralogist 35(6), 1571-1606.

Griddle, A. J. \& Stanley, C.J. (eds.) (1983): Quantitative Data File for Ore Minerais, $3^{\text {rd }}$ ed. Chápman \& Háll, London.

Dana, J. D. (1854): A System of Mineralogy, 4th ed. John Wiley \& Sons, New York.

Dana, J. D. (1868): A System of Mineralogy, 5th ed. John Wiley \& Sons, New York.

Donnay, G. \& Fleischer, M. (1970): Suggested outline for new mineral descriptions. American Mineralogist, 55, 1017-1019.

Dunn, P. J. (1977): From unknown to known: the cháracterization of new mineral species. Mineralogical Record, 8, 341-349.

Dunn, P. J. (1988): Protocols for scientists on the deposition of investigated mineral specimens. American Mineralogist, 73, 1480.

Dunn, P. J. (1990): The discreditation of mineral species. American Mineralogist 75, 928-929.

Dunn, P. J. \& Mandarine, J. A. (1987): Formal definitions of type mineral specimens. American Mineralogist, 72, 1269-1270.

Dunn, P. J. \& Mandarine, J. A. (1988): The Commission on New Minerais and Mineral Names of the International Mineralogical Association; its history, purpose and general practice. Mineralogical Record, 19, 319-323.

Fleischer, M. (1970): Procedures of the International Mineralogical Association Commission on New Minerais and Mineral Names. American Mineralogist, 55, 1016-1017.
Gladstone, J. H. \& Dale, T. P. (1864): Researches on the refraction, dispersion, and sensitiveness of the liquids. Philosophical Transactions of the Royal Society.. London, 153, 317-343.

Guinier, A., Bokij, G.B., Boll-Dornberger, K., Cowley, J.M., Durovic, S., Jagodzinski, H., Krishna, P., De Wolff, P.M., Zvyagin, B.B., Cox, D.E., Goodman, P., Háhn, Th., Kuchitsu, K. \& Abraháms, S.C. (1984): Nomenclature of polytype structures. Report of the International Union of Crystallography Ad-Hoc Committee on the Nomenclature of Disordered, Modulated and Polytype Structures. Acta Crystallographica, A40, 399-404.

Hárris, D. C. \& Cabri, L. J. (1991); Nomenclature of platinum-group-element alloys: review and revision. Canadian Mineralogist, 29, 231-237.

Hey, M. H. \& Gottardi, C. (1980): On the use of names, prefixes and suffixes, and adjectival modifiers in the mineralogical nomenclature. American Mineralogist, 65, 223-224.

Hey, M. H., Guillemin, C., Permingeat, F. \& de Roever, J. P. (1961): Sur la nomenclature Mineralogique. D6cisions de la Commission des Nouveaux MineYaux et des Nomes de Min6raux de L'Association Internationale de Mineralogie. Bulletin de la Societe francaise de Mineralogie et de Cristallographie, 84, 96-105.

Hogarth, D. D. (1977): Classification and nomenclature of the pyrochlore group. American Mineralogist, 62, 403-410.

Leake, B. E. et al. (1997): Nomenclature of amphiboles: Report of the Subcommittee on Amphiboles of the International Mineralogical Association Commission on New Minerais and Mineral Names. Canadian Mineralogist, 35, 219-246.

Levinson, A. A. (1966): A system of nomenclature for rare-earth minerais. American Mineralogist, 51, 152-158.

Makovicky, E. (1989): Modular classification of sulphosalts - current status. Definition and application of homologous series. Neues Jahrbuchfur Mineralogie, Abhándlungen 160, 269-297.

Makovicky, E. \& Hyde, B.C. (1981): Non-commensurate (misfit) structures. Structure and Bonding, 46, 103-176.

Makovicky, E. \& Karup-M011er, S. (1977): Chemistry and crystallography of the lillianite homologous series. Neues Jahrbuchfur Mineralogie, Abhándlungen, 130, 264-287.

Mandarine, J. A. (1981a): Comments on the calculation of the density of minerais. Canadian Mineralogist, 19, 531-534.

Mandarine, J. A. (1981b): The Gladstone-Dale relationship: Part IV. The compatibility concept and its application. Canadian Mineralogist, 19, 441-450.

CREFAUTOR = Mandarine, J. A. (1987): The check-list for submission of proposals for new minerais to the Commission on New Minerais and Mineral Names, International 
Mineralogical Association. Canadian Mineralogist, 25, 775-

783.

Mandarine, J. A., Nickel, E. H. \& Cesbron, F. (1984): Rules of procedure of the Commission on New Minerais and Mineral Names, International Mineralogical Association. Canadian Mineralogist, 22, 367-368.

Morimoto, N. (1990) Nomenclatura de piroxenios. (Tradução por Garda, G.M. \& Atencio, D.). Revista Brasileira de Geociencias 20(1-4), 318-328.

Nickel, E. H. (1991) Soluções sdlidas na nomenclatura mineralogica. (Traducao por Atencio, D.) Revista Brasileira de Geociencias 21(4), 387-389.

Nickel, E. H. (1998): Padronizafao de sufixos para politipos. (Tradufao por Atencio, D.). Revista Brasileira de Geociencias 28(3),

Nickel, E. H. (1995a): Definition of a mineral. Canadian Mineralogist, 33, $689-690$.

Nickel, E. H. (1995b): Mineral names applied to synthetic substances. Canadian Mineralogist, 33, 1335.
Nickel, E. H. \& Mandarino, J. A. (1990) Procedimentos envolvendo a Comissão de Novos Minerais e Nomes de Minerais da IMA, e diretrizes sobre nomenclatura mineral. (Tradução por Atencio, D. \& Garda, G.M.). Revista Brasileira de Geociencias 20(1-4), 302-317.

Ramsdell, L. S. (1947): Studies on silicon carbide. American Mineralogist, 32, 64-82.

Rieder, M. et al. (1998) Nomenclature of the micas. Canadian Mineralogist 36 (no prelo)

Scháller, W. T. (1930): Adjectival ending of chemical elements used as modifiers to mineral names. American Mineralogist, 15, 567-574.

Veblen, D. R. (1991): Polysomatism and polysomatic series: a review and applications. American Mineralogist, 76, 801-826.

Manuscrito A-1003

Recebido em 30 de junho de 1998 Aprovado para publicação em 30 de julho de 1998 


\section{APENDICE I}

\section{MEMBROS DA COMISSÃO DE NOVOS MINERAIS E NOMES DE MINERAIS DA IMA (em agosto de 1998)}

\section{EXECUTIVO}

Presidente: Dr. J. D. Grice, Canadian Museum of Nature, PO Box 3443 , Station "D", Ottawa, Ont., CANADA KIP 6P4. E-mail: jgrice@mus-nature.ca

Vice-presidente: Prof. G. Ferraris, Dip. di Scienze Mineralogiche e Petrologiche, Universita di Torino, Via Valperga Caluso 35, 210125 Torino, ITALY.E-mail: ferraris@dsmp.unito.it

Secretario: Dr. W. D. Birch, Department of Mineralogy, Museum of Victoria, 285 Russell Street, Melbourne, Vie. 3000, AUSTRALIA. E-mail: bbirch@mov.vic.gov.au

\section{REPRESENTANTES NACIONAIS}

Africa do Sul: Dr. J. P. R. de Villiers, Mineralogy Division, Council for Mineral Technology, Private Bag X3015, Randburg 2125, SOUTH AFRICA.

Alémanhá: Dr. P. Keller, Institut fiir Mineralogie und Kristallchemie, Universitat Stuttgart, Pfaffenwaldring 55, D-7000 Stuttgart, GERMANY

Australia: Dr. Allan Pring, Department of Mineralogy, South Australian Museum, North Terrace, Adelaide, S.A. 5000, AUSTRALIA. E-mail: apring@geology.adelaide.edu.au

Austria: Prof. Dr. F. Pertlik, Institut fiir Mineralogie und Kristallographie, Universitat Wien, Althánstrasse 14, A-1090 Wien, AUSTRIA. E-mail: Franz.Pertlik@univie.ac.at

Belgica: Dr. M. Deliens, Section de Mineralogie, Institut royal des Sciences naturelles, Rue Vautier, 29, B-1000 Bruxelles, BELGIUM

Brasil: Dr. Daniel Atencio, Institute de Geociencias, Universidade de São Paulo, Caixa Postal 11348, 05422-970 São Paulo, SP, BRASIL. E-mail: datencio@usp.br.

Bulgaria: Prof. Ivan Kostov, National Natural History Museum, Bulgarian Academy of Sciences, Boulv. Tsar Osvoloditel 1000, Sofia, BULGARIA.E-mail: rikostov@staff.mgu.bg

Canada: Mr. A. C. Roberts, Geological Survey of Canada, 601 Booth Street, Ottawa, Ont., CANADA K1A OE8.E-mail: aroberts@nrcan.gc.ca

China: Dr. Huang Yunhui, Institute of Mineral Deposits, Chinese Academy of Geological Sciences, Baiwanzhuang Road 100037, Beijing, CHINA

Croatia: Dr. V. Bermanec, Mineral.-Petrog. zavod PMF-a, University of Zagreb, Demetrova 1/1, HR-41000 Zagreb, CROATIA.

Dinamarca: Dr. Ole Johnsen, Geologisk Museum, Oster Voldgade 5, DK-1350 Copenhágen K, DENMARK. E-mail: oj@savik.geomus.ku.dk

Eslovaquia: Dr. Pavel Uher, Geological Institute, Slovak Academy of Sciences, Dubravska cesta 9,842 26 Bratislava, SLOVAKIA. E-mail: geoluher@savba.savba.sk

Espanhá: Prof. Dr. P. F. Hách-Ali, Departamento de Mineralogfa y Petrologia, Avda. Fuentenueva s/n, Universidad de Granada, Granada 28002, SPAIN.E-mail: pfenoll@goliat.ugr.es
Estados Unidos: Dr. P. J. Dunn, Department of Mineral Sciences, Smithsonian Institution, Washington, DC 20560, USA

Finlandia: Prof. Ragnar Tornroos, Department of Geology, University of Helsinki, PO Box 11 (Snellmaninkatu 3), FIN-00014 University of Helsinki, FINLAND

França:Dr. Y. Moelo, Institut des Matériaux de Nantes, Laboratoire de Chemie des Solides 2, rue de la Houssiniere, 44332 Nantes Cedex 03, B.P. 32229, FRANCE. E-mail: Yves.Moelo@cnrs-imn.fr

Holanda: Dr. E. A. J. Burke, Faculteit Aardwetenscháppen, Vrije Universiteit, De Bolelaan 1085, 1081 HV Amsterdam, THE NETHERLANDS. £-wat7:bure@geo.vu.nl

Hungria: Dr. Gabor Papp, Hungarian Natural History Museum, Department of Mineralogy \& Petrology, Budapest, Pf.: 137, H-1431, HUNGARY. E-mail: pappmin@ludens.elte.hu

Israel: Dr. Hánan J. Kisch, Department of Geology \& Mineralogy, Ben-Gurion University of Negev, PO Box 653, Beer-Sheva 84105, ISRAEL

Italia: Prof. G. Ferraris, Dip. di Scienze Mineralogiche e Petrologiche, Universita di Torino, Via Valperga Caluso 35,210125 Torino, ITALY. E-mail: ferraris@dsmp.unito.it

Japao: Dr. Satoshi Matsubara, Department of Geology, National Science Museum, 3-21-1 Hyakunin-cho, Shinjuku, Tokyo 160. JAPAN. E-mail: matubara®.kaháku.go.jp

Noruega: Dr. Gunnar Raade, Mineralogisk-Geologisk Museum, Sars' Gate 1, N-0562 Oslo, NORWAY.E-mail: gunnar.raade@toyen.uio.no

Nova Zelandia: Prof. D. S. Coombs, Department of Geology, University of Otago, PO Box 56, Dunedin, NEW ZEALAND. E-mail: doug.coombs@stonebow.otago.ac.nz

Polonia: Prof. Dr. A. Manecki, Academy of Mining \& Metallurgy, Institute of Geology \& Mineral Deposits, al. Mickiewicza 30, 30-059 Krakow, POLAND

Reino Unido: Dr. Alan Criddle, The Natural History Museum, Cromwell Road, London SW7 5BD, ENGLAND.E-mail: a.criddle@nhm.ac.uk

Republica Tcheca: Dr. Milan Novak, Dept. of Mineralogy \& Petrology, Moravian Republic Museum, Zelny trh 6, 65937 Brno, CZECH REPUBLIC.E-mail: mineral@mzm.anet.cz

Romenia: Dr. G. Udubasa, Institute of Geology \& Geophysics, Str. Caransebes No. 1,78344 Bucuresti-32, ROMANIA. E-mail: udubasa@igr.sfos.ro

Russia: Prof. A. G. Bulakh, Department of Mineralogy, St. Petersburg University, Universitetskaya nab., 7/9, St. Petersburg 199034, RUSSIA.E-mail: bulakh@mineral.geol.pu.ru

Suecia: Dr. Ulf Hálenius, Department of Mineralogy, Naturhistoriska Riksmuseet, Box 50007, S-104 05 Stockholm, SWEDEN

80193: Prof. S. Graeser, Naturhistorisches Museum, Augustinergasse 2, CH-4051 Basel, SWITZERLAND. E-mail: graesers@ubaclu.unibas.ch

WEB Site: http://www.dst.unipi.it/ima/ 


\section{APÊNDICE ॥}

\section{MUDANÇAS NA NOMENCLATURA (1987-1998)*}

\section{Desacreditações}

Andrewsita (= hentschelita)

Anosovita (= armalcolita)

Ashánita (= ixiolita)

Baumita (= serpentina impura)

Bravoíta (= pirita com Ni)

Calciocelsiana (= armenita)

Cálcio farmacossiderita (= bário farmacossiderita)

Caratiita (= piypita)

Chávesita (= monetita)

Coutinhita (= lantanita-(La))

Coutinita (= lantanita-(Nd))

Csiklovaíta (= tetradimita)

Cuprocassiterita ( $=$ mushistonita)

Donathita $(=$ magnetita + chromita $)$

Ferrazita (= gorceixita)

Ferropseudobrookita (= pseudobrookita)

Herschelita (= chábazita)

Iridosmina (= ósmio)

Kehoíta (uma mistura)

Kennedyíta (= armalcolita)

Laubmannita (= dufrenita impura)

Leonhárdita (= starkeyíta)

Lusungita (= goyazita)

Maufita (= lizardita/clorita interestratificadas)

Neodimita (= lantanita-(La) ou lantanita-(Nd))

Nioboloparita (= loparita-(Ce))

Osmirídio (= irídio)

Platinirídio(= irídio)

Polimignita (= zirkelita)

Portita (= natrolita)

Protoastrakhánita (= konyaíta)

Ranita (= gonnardita)

Rezbanyíta (= mistura com hámmarita)

Ruteniridosmina (= irídio)

Selen-telúrio (= selênio + tellúrio)

Sismondina (= cloritóide)

Staringita (= cassiterita + ferrotapiolita)

Sulrhodita (= bowieíta)

Svetlozarita (= dachiardita)

Tetranatrolita (= gonnardita)

Ureyíta (= kosmocloro)

Viseíta (= crandallita desordenada)

Warrenita (= jamesonita)

Wellsita (= phillipsita e hármotomo)
Dunn: Am. Min. 75 (1990), 1197

Bowles: Am. Min. 73 (1988), 1377

Pendente

Guggenheim \& Bailey: Am. Min. 75 (1990), 705

Bayliss: Am. Min. 74 (1989), 1168

Mason: Min. Mag. 51 (1987), 317

Pendente

Filatov \& Vergasova: ZVMO 118 (3) (1989), 88

Kampf\&Dunn: Am. Min. 79(1994), 385

Pendente

Pendente

Bayliss: Am. Min. 76 (1991), 257

Dunn \& Roberts: Min. Rec. 17 (1986), 383

Burns et al.: N. Jb. Min. Mh. 1997, 163

Atencio \& Clark: Min. Mag. 60 (1996), 841

Bowles: Am. Min. 73 (1988), 1377

Coombs et al. Can. Min. 35 (1997), 1571

Hárris \& Cabri: Can. Min. 29 (1991), 231

Coombs et al.: Can. Min. 35 (1997), 1571

Bowles: Am. Min. 73 (1988), 1377

Dunn: Am. Min. 75 (1990), 1197

Coombs et al: Can. Min. 35 (1997), 1571

Pring et al:Min. Mag. 59(1995), 143

Pendente

Pendente

Mitchell et al: Can. Min. 34 (1996), 991

Hárris \& Cabri: Can. Min. 29 (1991), 231

Hárris \& Cabri: Can. Min. 29 (1991), 231

Bayliss ef a/.: Min. Mag. 53(1989), 565

Franzini \& Perchiazzi: Europ. Jour. Min. 6 (1994), 351

van Doesburg \& van der Pias: Am. Min. 74 (1989), 1382

Coombs et al.: Can Min. 35 (1997), 1571

Zak \& Mumme: N. Jb. Min. Mh. (1994), 314

Hárris \& Cabri: Can. Min. 29 (1991), 231

Bayliss: Am. Min. 76 (1991), 257

Chopin et al: Europ. Jour. Min. 4 (1992), 67

Groat et al: Min. Mag. 58 (1994), 271

Bayliss et al: Min. Mag. 56 (1992), 125

Coombs et al: Can. Min. 35 (1997), 1571

Pendente

Morimoto et al: Min. Mag. 52 (1988), 535

Coombs et al: Can. Min. 35 (1997), 1571

Pendente

Coombs et al: Can Min. 35 (1997), 1571 


\section{Redenomínações}

Acmita (= egirina)

Analcita (= analcima)

Crossita (= glaucofânio, etc.)

Dannemorita (= manganogrunerita)

Edenita silícica(= edenita)

Fassaíta (= diopsídio ou augita)

Ferridravita (= povondraíta)

Ferro-edenita silícica (= ferro-edenita)

Fiedlerita (politipos)

Ginzburgita de Voloshin et al. (= roggianita)

Gismondita (= gismondina)

Hástingsita com $\mathrm{Mg}$ (= magnesiohástingsita ou hástingsita)

Herschelita (= chábazita-Na)

Hiortdahlita (polimorfos)

Hiperstênio (= enstatita or ferrossilita)

Hornblenda actinolítica (= magnesiohornblenda)

Hornblenda edenítica (= edenita)

Hornblenda ferro-actinolítica (= ferrotschermakita

Hornblenda ferro-edenítica $(=$ ferro-edenita $)$

Hornblenda ferro-pargasítica (= ferropargasita)

Hornblenda ferro-tschermakítica (= ferrotschermakita)

Hornblenda hástingsítica (= hástingsita)

Hornblenda hástingsítica com $\mathrm{Mg}$ (= magnesiohástingsita ou

hástingsita)

Hornblenda magnésio-hástingsítica (= magnesiohástingsita)

Hornblenda pargasítica (= pargasita)

Hornblenda pargasítica com $\mathrm{Fe}$ (II) (= pargasita ou ferropargasita)

Hornblenda tremolítica (= magnesiohornblenda)

Hornblenda tschermakítica (= tschermakita)

Leonhárdita (= laumontita)

Magnésio-antofilita (= antofilita)

Magnésio-clinoholmquistita (= clinoholmquistita)

Magnésio-cummingtonita (= cummingtonita)

Magnésio-gedrita (= gedrita)

Magnésio-holmquistita (= holmquistita)

Magnésio orthita (= dollaseíta-(Ce))

Natroautunita (= meta-natroautunita)

Pargasita (= pargasita ou ferropargasita)

Penkvilskita (politipos)

Sódio-antofilita (= sodicantofilita)

Sódio dachiardita (= dachiardita-Na)

Sódio gedrita

Tirodita (= manganocummingtonita)
Morimoto et al.: Min. Mag. 52 (1988), 535

Coombs et al: Can Min. 35 (1997), 1571

Leake et al: Can. Min. 35 (1997), 219

idem

idem

Morimoto et al: Min. Mag. 52 (1988), 535

Grice et al: Am. Min. 78 (1993), 433

Leake et al: Can. Min. 35(1997), 219

Merlino et al.: Min. Mag. 58 (1994), 69

Coombs et al.: Can Min. 35 (1997), 1571

idem

Leake et al: Can. Min. 35(1997), 219

Coombs et al.: Can Min. 35 (1997), 1571

Merlino \& Perchiazzi: Min. Petrol. 37 (1987), 25

Morimoto et al.: Min. Mag. 52 (1988), 535

Leake et al.: Can. Min. 35 (1997), 219

idem

idem

idem

idem

idem

idem

idem

idem

idem

idem

idem

idem

Coombs et al: Can. Min. 35 (1997), 1571

Leake et al.: Can. Min. 35 (1997), 219

idem

idem

idem

idem

Peacor \& Dunn: Am. Min. 73 (1988), 838

Chernikov \& Organova: Dokl. Akad. Nauk 338 (1994), 368

Leake et al.: Can. Min. 35 (1997), 219

Merlino et al.: Am. Min. 79 (1994), 1185

Leake et al: Can. Min. 35 (1997), 219

Coombs et al.: Can Min. 35 (1997), 1571

Leake et al: Can. Min. 35 (1997), 219

idem 


\section{Redefinições}

Aguilarita

Armalcolita

Attakolita

Berndtita (politipos)

Gartrellita

Georgeíta

Kegelita

Khádemita

Plumbotelurita

Pseudobrookita

Ruteniridosmina

Tengerita-(Y)

Villamaninita

Xitieshanita

Zirconolita (polimorfos)

Zirkelita

\section{Reválidações}

Aerinita

Bário farmacossiderita

Fernandinita

Prismatina

Pseudo-rutilo
Pendente

Bowles: Am. Min. 73 (1988), 1377

Grice \&Dunn: Am. Min. 77 (1992), 1285

Bayliss \& Clark: Min. Mag. 54 (1990), 137

Krause et al: Eur. J. Min. 10 (1998), 179

Pollard et al: Min. Mag. 55 (1991), 163

Dunn et al: Am. Min. 75 (1990), 702

Cesbron \& Bayliss: Min. Mag. 52 (1988), 133

Pendente

Bowles: Am. Min. 73 (1988), 1377

Hárris \& Cabri: Can. Min. 29 (1991), 231

Miyawaki et al: Am. Min. 78 (1993), 425

Bayliss: Am. Min. 74 (1989), 1168

Li Jiaju et al: Sei. Geol. Sinica (1989), 106

Bayliss et al: Min. Mag. 53 (1989), 565

Bayliss et al: Min. Mag. 53 (1989), 565

Azambre \& Monchoux: Buli. Min. 111 (1988), 39

Walenta: Aufschluss45 (1994), 73

Evans et al: Can. Min. 32 (1994), 339

Grew et al: Min. Mag. 60 (1996), 483

Grey et al: Min. Mag. 58 (1994), 597 